\title{
Aporte cultural de Santa Rosa de Lima: sus coplas, Mercedes y Escala mística
}

Santa Rosa de Lima's cultural contribution: its coplas, Mercedes and Escala mística

Uno de los temas más fascinantes de la historia hispanoamericana del siglo XVII es el de las beatas, mundo religioso del cual Santa Rosa de Lima formó parte. La figura de la santidad, en el lapso que va desde 1580 a 1620, ha sido un fenómeno virreinal que, mayormente, ha originado reflexiones piadosas y muy pocas desde la perspectiva científica. Es claro que en dicho lapso, en el Virreinato del Perú se originó un movimiento místico que hizo ingresar a Lima virreinal en una tradición de santidad que comenzó en el Occidente cristiano en la Edad Media, cuando Clara de Montefalco (1268-1308), Angela de Foligno (1248-1309), Brígida de Suecia (1302-1373) y Catalina de Siena (13471380) revolucionaron el papel de la mujer dentro del cristianismo. La existencia de estas devotas, provocó un impacto en la sociedad limeña, lo cual se refleja en la figura de Santa Rosa de Lima (1586-1617) y en la influencia que ella ejerció en sus contemporáneas.

La condición de beata era ante todo una opción personal, que rechazaba tanto el matrimonio como el convento, la autoridad paterna y la dominación conyugal. Rosa de Lima es el prototipo de las mujeres que "se dejaron seducir por el Amor" (Muriel, 1992: 300) y a él se entregaron. Hermosa, atractiva y bien educada, fue requerida en matrimonio, empero lo rechazó, despreció elogios, posición, comodidades y avasalló todo interés humano. Santa Rosa de Lima fue una beata mo-

Peruana. Magíster en Educación, Magíster en Derecho Público, Estudiante del Programa de Doctorado en Humanidades con mención en Cultura, Universidad de Piura, Perú. Académica, Universidad de Piura, Perú. E-mail: zhenia.aparicio@udep.pe 
delo entre todas, en vista de que rehusó la clausura conventual y vistió hábito de terciaria dominica en su hogar, antes de que se fundara en Lima el monasterio dominico de Santa Catalina en 1624, años después de su muerte.

Conforme lo señala José Antonio del Busto (2006: 342), Santa Rosa de Lima era una mujer cultivada mental y espiritualmente, pero ello no se debió a estudios superiores. Se debió a ella misma: fue autodidacta. No tuvo maestros, solo confesores y guías espirituales, algo usual en la época. Isabel Flores de Oliva, nombre con que fuera bautizada la santa, fue la primera persona nacida en América que mereció el privilegio de ser canonizada por la Iglesia de Roma. Ese breve espacio de vida, de 31 años, que tuvo Isabel Flores de Oliva nos muestra un legado de piedad y de recogimiento y ya, desde muy pequeña, se diferenciaba de todas las demás por una admirable resignación que en su tierna edad era incomprensible.

La santa no fue ajena al dolor de la humanidad, tan es así que, al igual que la santa dominica Catalina de Siena, Rosa de Lima desarrolló una teología cristocéntrica y eucarística que le permitió identificarse con la humanidad sufriente, maternal y redentora de Jesús. El último milagro que Santa Rosa obra en vida es la prueba de cariño otorgada a su madre, pues ésta, al verla agonizar, ve transformado su dolor en un goce sobrenatural, que la obliga a dar saltos de júbilo cuando su hija expira.

El biógrafo dominico alemán Leonardo Hansen (2001: 35-36) relata el incidente del siguiente modo, "En el último trance de la muerte, estando ya para partirse el alma, miró Rosa a su madre, que estaba a su cabecera, con el dolor que la ocasión pedía. Y no ignorando que había de ponerla en punto de perder la vida (...), rogó a su Esposo (...) que tomase a su cuenta dar a su madre ánimo y valor en tan apretado lance (...) Así sucedió (...); en expirando la virgen, fueron tantas las avenidas de consuelo y gozo que desde lo alto inundaron el corazón de la afligida madre, que la obligaron (...) a hacerse mucha violencia a sí misma, para no manifestar la alegría, sin poder sufrir por largo espacio de tiempo tanto raudal de dulzuras como sintió su pecho; tanto que casi no podía contenerse sin dar saltos de placer".

Santa Rosa de Lima es para el Perú del s. XVII, compartiendo lo señalado por Mujica Pinilla (2001: 41), lo que la Virgen de Guadalu- 
pe es para México del XVIII, y Santa Teresa de Jesús para la España de la Edad Media o del Barroco. Así, el éxito referido a su acelerada canonización se debe a variados factores que Graziano (2002: 9-39) nos detalla: "la elevada consideración de su humildad y ascetismo penitente, el auspicio de su candidatura por parte de varios grupos de interés, la efectiva construcción hagiográfica de su identidad, su enorme devoción pública y la tendencia generalizada de las canonizaciones reformistas en direcciones que favorecían su candidatura, entre ellas la prominencia de los santos hispanos, el incremento en la beatificación de las mujeres, la preferencia por su manera de ser santa, y el desplazamiento de monarcas y nobles santos por gente del común".

De lo señalado podemos constatar que Santa Rosa de Lima es considerada como un modelo legítimo de perfección cristiana. Poco después de su muerte, la fama de la santidad de su vida se extendió por los océanos hasta España y otros países católicos de Europa. Clérigos, dramaturgos, poetas, pintores y escultores perpetuaron en sus trabajos el nombre de "Rosa de Lima", tal como lo apreciamos en la influencia que tuvo ya en el siglo XX en pintores como Teófilo Castillo Guass en su obra Funerales de Santa Rosa de Lima (figura $\mathrm{N}^{\circ} 1$ ).

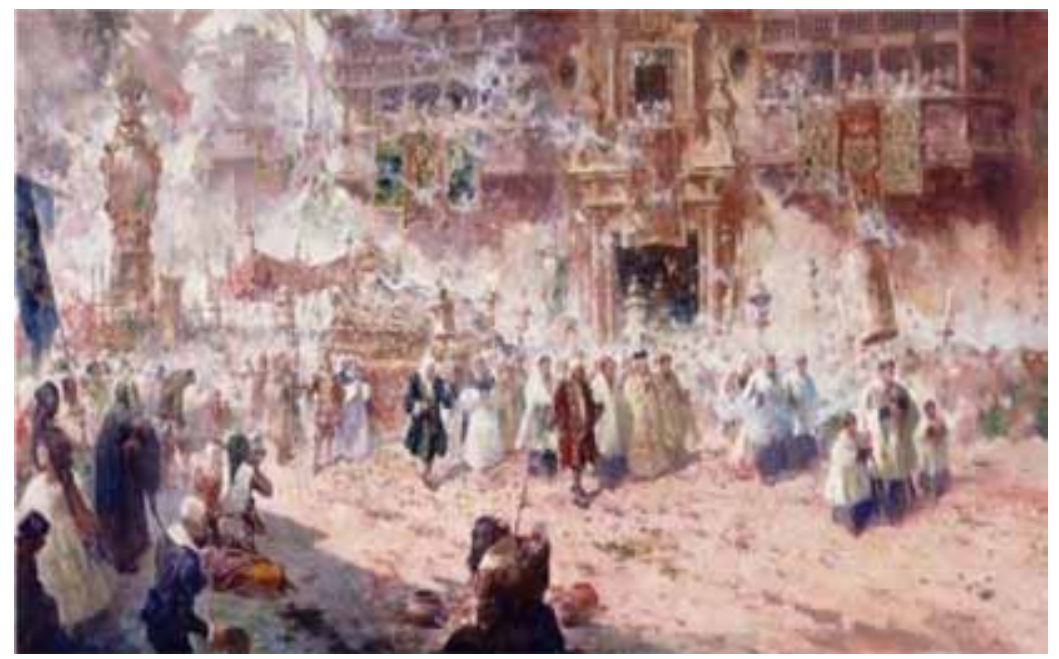

Figura $N^{\circ} 1$. Funerales de Santa Rosa (1918), de Teófilo Castillo.

Fuente: Museo de Arte de Lima, Donación Memoria Prado. 


\section{Influencias espirituales de la santa limeña}

Habiendo mencionado brevemente la biografía de Rosa de Lima, es imperante, para entender su influencia espiritual, hacer acotación de que, a finales del s. XVI, llegaron al Perú las preferencias místicas, principalmente de Santa Teresa de Jesús, San Juan de la Cruz y sus fieles seguidores. Esto llevó a concientizar que la vida contemplativa se entendía a partir de las obras como laborales asistenciales, penalidades personales (por ejemplo, las disciplinas que muchas veces se imponía Santa Rosa de Lima o el ayuno) y oraciones, estando esto aceptado por las órdenes religiosas activas y admitidas por España en el Perú. En consecuencia, ¿cuáles fueron las influencias espirituales que tuvo la santa limeña para llevar su vida a la perfección?

Rosa fue lectora desde muy temprano. Su hermano Hernando asegura que aprendió a leer "desde edad de sus tiernos años" y que, regularmente, se le hizo costumbre leer "libros devotos" (Del Busto, 2006: 184), así como obra fundamental que ayudó a forjar su sacralidad. Entre ésta se encuentra el Cantar de los Cantares del Antiguo Testamento, el cual celebra el matrimonio místico querido por Dios. Asimismo, podemos mencionar la raíz franciscana, poco tomada en cuenta en las obras biográficas de la santa.

Los biógrafos que han analizado esta influencia nos relatan que, antes de imponerle los dominicos el hábito de terciaria, en la capilla de Nuestra Señora del Rosario, Santa Rosa ya había usado por varios años el hábito franciscano y lo mantuvo siempre. Y esto es importante, en virtud que se llega a comprender de manera más clara la piedad de la santa.

Rosa de Lima dejó al arbitrio de cuatro teólogos la decisión acerca de qué orden tomar el hábito. Señala su biógrafo Hansen: "Pero ella, con toda humildad, dejó que cuatro teólogos dominicos decidieran que como el divino Hortelano había plantado en el cuartel Seráfico la Rosa de Viterbo, quiso dejar la de Lima para el jardín de Domingo" (Mujica Pinilla, 2004: 37).

Al hacer referencia a la Rosa de Viterbo, Gonzáles de Acuña (2004: 84) recuerda la historia de cuando "Gonzalo de la Maza, confidente de la santa, le dio a leer la biografía de la virgen franciscana Santa Rosa de Viterbo, cuya vida de renuncia admiró e imitó, pero ella decidió dejar 
en las manos de los sabios dominicos su entrada a la orden. Así, la virgen limeña se impuso sin titubeos su saco de sayal recoleto franciscano por el hábito de beata dominica". A pesar de su afinidad hacia los dominicos, no se descarta que Santa Rosa de Lima, conforme a las evidencias dejadas de su vida, nunca abandonara su cercanía espiritual hacia los franciscanos, y sobre todo hacia su piedad naturalista, proyección clara de esta orden mendicante.

Así, para los seguidores de San Francisco de Asís, el mundo natural había quedado santificado con la encarnación de Dios, la creación era un ícono inmenso, repleto de signos y mensajes codificados, destinados a guiar paulatinamente el entendimiento del hombre hacia Dios. La Santa de Lima, con esta misma inclinación, nos recuerda la grandeza de Dios. Cuando en ocasiones algunas mujeres entraban en el huerto y alababan su floresta, ella respondía: "Hermoso está el jardín y vistoso, Dios dé mucho aumento a sus flores", refiriéndose al "vergel del alma", por el cual pedía "aumento florido de virtudes" (Mujica Pinilla, 2004: 41).

Siguiendo la línea de una influencia hacia el amor a la realidad circundante, dentro de sus composiciones Santa Rosa de Lima alude a coplas que envuelven lo natural y cotidiano que "se apoyan en un conocimiento vivencial y práctico que desconoce los principios de la literatura culta" (Carrasco Ligarda, 2016: 161) y, como ejemplo, tenemos su famosa copla:

"Pajarito ruiseñor alabemos al Señor. Tú alaba a tu criador yo alabaré a mi Salvador" y este cantar lo enfatiza en el último año de su vida, pues lo hace siguiendo una tradición franciscana, a las seis de la tarde y durante la cuaresma.

Para esto, Hensen, su biógrafo, citado por Mujica Pinilla (2004: 43), invocando el don musical de Rosa y basándose en las declaraciones del proceso ordinario de canonización, señala "También tocaba arpa, cítara y vihuela, y a sus confesores les decía: "Quitarme a mí el cantar es quitarme el comer". Con una guitarra de dos cuerdas cantaba "a vozes sin reparar en la gente que la podía oyr de su casa" y le decía "mil requiebros al niño Jesús recién nacido en su pesebre".

Otra fuerza espiritual fue Catalina de Siena, sobre todo en la vida de abstinencias que acompañó a la santa. Este modelo de vida era común en numerosas beatas durante el Renacimiento y la Reforma Católica, 
las cuales ya habían leído la biografía de Catalina, escrita por su confesor Raimundo de Capua (1330-1339), siguiendo éstas gran parte de su espiritualidad.

Tanto Santa Catalina como Rosa de Lima entendían el ayuno como el camino de penitencia hacia la cruz, ejemplificando claramente ese homo penitente heredado del mundo medieval. Así, como manifestación de vida, a los 12 años Catalina de Siena se cortó los cabellos en rebelión a sus padres, quienes querían presentarle pretendientes para casarla; Santa Rosa, a la misma edad y por emular a Catalina, se cortó los suyos, pues aseguraba que los cabellos eran el punto hacia el mal que esclavizaba las almas.

Los dominicos se constituyen como una tercera influencia en la Santa Limeña. Uno de sus confesores, a no decir el más cercano, fue el padre dominico Pedro de Loayza. Durante el proceso de elevación de Rosa de Lima a los altares, el 4 de marzo de 1630, se abre el expediente apostólico de declaración de testigos sobre la devoción, penitencia, dones preternaturales y santa muerte de Isabel Flores de Oliva. Este proceso dura dos años y es en este proceso complementario cuando se anexa una copa de la biografía de este padre dominico Vida, muerte y milagros de sor Rosa de Santa María, escrita en 1619.

Podemos decir que la influencia de los dominicos en Rosa de Lima fue dirigida a la propagación de su santidad, pues, si bien es cierto fueron un basamento para Rosa en la asimilación de su espiritualidad, fueron ellos los que se encargaron, a través de las confesiones de la Santa, de acercar a la misma a su creciente público y su difusión por esta orden se propagó hasta después de su muerte.

\section{El don musical y poético de Rosa de Santa María}

Ya expuestas de manera general las principales influencias espirituales de Rosa de Lima, abordaremos cómo estas, de una u otra manera, contribuyeron a su producción intelectual muy poco estudiada en la historia de su santidad ${ }^{1}$. A su vez, de acuerdo con la realidad histórica

1 El último estudio de la Santa limeña lo encontramos en la investigación de Rosa Carrasco Ligarda: "Santa Rosa de Lima: Escritos de la Santa Limeña" para mayor información se puede revisar la reseña realizada a esta obra en el Mercurio peruano $\mathrm{N}^{\circ} 530 \mathrm{del}$ año 2017 por la autora del presente artículo. 
de la época en que vivió la santa (s. XVI y XVII), en el Perú la educación no tenía en cuenta la formación letrada de las mujeres, por ende, un escaso número de ellas sabía leer y escribir, y esto, claro está, se aprecia en la producción intelectual de Rosa de Lima, aunado al hecho de que existía una "imposibilidad de las mujeres de acceder a fuentes bibliográficas de alto nivel intelectual, o a centros de formación superior que les permitiesen cimentar una cultura superior" (Carrasco Ligarda, 2016: 14).

Teniendo en cuenta el escenario en que la actividad de Santa Rosa se dio, no podemos negar que su influencia espiritual e intelectual debe ser resaltada, en vista de que su irradiación se asentó en muchas beatas que le siguieron, así como también se vieron afectados con su espiritualidad artistas y poetas de la época, sin descartar la inspiración actual que hasta hoy en día despierta.

\section{Sus coplas}

Sobre la dote musical de Rosa de Lima, su hermano Hernando Flores de Herrera, tal como consta en su declaración en el proceso de canonización de la Santa, una vez le preguntó: “¿Quién le enseña tantos cantarcicos, hermana?". Rosa respondió: "Hermano, como hay tanto que decir de nuestro buen Padre, ofrécense con facilidad sus alabanzas".

Sabemos que la Santa vivía apartada de las habitaciones familiares, en una celda pequeña y húmeda construida en un ángulo del jardín, donde llevaba una vida de oración y trabajos intensos. La fama de Rosa llevó a su celda del jardín a algunas de las damas más aristócratas de Lima, las cuales, además de meditar y orar, eran acogidas como en un lugar de ocio, en el que las mujeres se reunían para pasar el rato y divertirse "de manera honesta" (Martín, 2000: 303).

Generalmente, estas mujeres escuchaban a Rosa, la cual tenía una voz muy agradable para el canto y tocaba la guitarra con bastante pericia y sentimiento. También escribía versos excelentes y, como santa Teresa de Ávila, poseía el extraordinario talento de transformar las canciones de amor populares en hermosas "coplas a lo divino". Uno de sus poemas más hermosos, probablemente inspirado en una canción de amor popular de la época, consiste en un delicioso juego de palabras con los apellidos de la familia y su nombre (Del Busto, 2006: 282): 
Oh, Jesús de mi alma,

¿Qué hermoso estás!

Entre rosas y flores

$Y$ de olivo verdes rama.

Es medianoche ya,

Mi Jesús no ha llegado

¿Quién será el afortunado

que lo guarda?

La vertiente literaria de Rosa de Lima se llena de este tipo de composiciones que, conforme a sus testigos, las entonaba de forma frecuente dentro de sus oraciones. En este sentido, "[e]stas versiones orales transmitidas por terceros constituyen la única fuente, hasta ahora, que permite una aproximación a esta vertiente creativa. Son numerosos los testigos, ya que la vida de Rosa se desenvolvió fuera de los recintos de clausura, y hubo laicos y religiosos que la escucharon" (Carrasco Ligarda , 2016: 156).

A su vez, Rosa de Lima, en momentos de soledad y sufrimiento, pasaba horas con su guitarra y expresaba sus sentimientos en unas coplillas que se le escucharon muchas veces:

\section{Las doce son dadas}

Mi Jesús no viene.

¿Quién será la dichosa que le entretiene?

(Carrasco Ligarda, 2016: 163) ${ }^{2}$

El tópico que gira en sus coplas, de manera reiterada, es el amor, pues constituye uno de sus ejes neurálgicos, por no decir tradicionales. El amor, y dirigido a Jesús, es para ella fuente de inspiración, al que se suman otros motivos evidentes en sus versos, como son la alegría y la pena. La cercanía entre Rosa y Jesús, "su doctorcito" ${ }^{3}$ (figura $\mathrm{N}^{\circ} 2$ ), se ve

2 Conforme lo señala Carrasco Ligarda (2016: 159), el rescate de las coplas de Rosa de Lima se basa en fuentes manuscritas y en publicaciones, entre las fuentes manuscritas se encuentra el Expediente del Proceso Ordinario y el Proceso Apostólico. El Expediente se inició el 5 de septiembre de 1617, ocho días después del fallecimiento de Rosa de Santa María, este documento se encuentra en el monasterio de Santa Rosa de Lima. El segundo documento se levantó de 1630 a 1632, y se encuentra en el Archivo Arzobispal de Lima. 3 Santa Rosa de Lima es conocida también por su actividad milagrosa, sobre todo a los enfermos. La realizaba en nombre de una imagen de Jesús a la cual le denominaba 
reflejado en muchas obras posteriores a la muerte de la santa limeña, sobre todo, en la pintura cuzqueña que data entre los siglos XVI y XVIII.

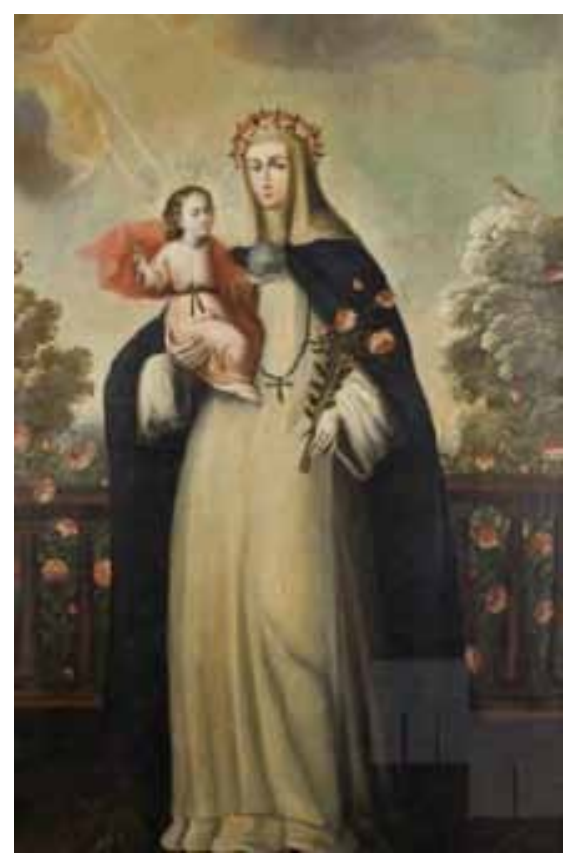

Figura $N^{\circ}$ 2. Santa Rosa de Lima con el Niño Jesús (ca.1680-1700), anónimo cuzqueño.

Fuente: Museo de Arte de Lima.

Los motivos de sus coplas se plasmaban en un melodioso canto y, siguiendo a Carrasco Ligarda, se identificaban como villancicos, canciones típicas españolas del siglo XVI, aunado al hecho de que el canto "dentro del rito religioso católico fue impulsado por el Concilio de Trento, que dispuso que las ceremonias religiosas fuesen acompañadas de todo el lustre posible" (Carrasco Ligarda, 2016: 162).

Sin embargo, estas coplillas no fueron estrictamente de invención de la santa limeña. En esta línea, Rosa, al igual que otros místicos de su tiempo, adapta los temas amorosos profanos al mundo religiosoespiritual. Por ejemplo, la santa se inspira en la Comedia de Calisto y 
Melibea, de 1499, novela picaresca española que contiene una copla de este estilo: "La media noche es pasada, y no viene, sabedme si hay otra amada, que lo detiene".

El huerto de su casa fue también testigo de su canto y poesía, conforme lo señala José Antonio del Busto (2006: 283), en presencia de dos de sus amigas, Catalina de Santa María y su hermana Lucía. Muchos días acudía un pajarillo, se posaba en la rama de un guayabo y merecía que Rosa le dijera a manera de saludo:

Pajarito Ruiseñor,

Alabemos al Señor,

Tú alaba tú a tú criador,

yo alabaré a mi Señor.

(Carrasco Ligarda, 2016: 163).

Y con tales palabras empezaba el pajarillo a cantar y después se callaba para que cantara Rosa, propiciando con sus dotes musicales una reunión y alabanza con Dios (Del Busto, 2006: 283):

¡Oh, mi Dios, si yo te amara!

¡Oh, si te amara, mi Dios!

¡Y amándote me quedara

Ardiendo en llamas de Amor!

¿Cómo te amaré mi Dios?

¿Cómo te amaré, Señor?

Siendo yo tu criatura

Y tú el Criador.

No hay duda de que en estos cánticos el tema de la alabanza se torne recurrente. Siendo el pajarillo un elemento importante en el diálogo yo-pajarillo, se conjugan tan bien que la alabanza se convierte en agradecimiento al creador. El pajarillo es el reflejo de la existencia terrenal del salvador, plasmándose esa relación "creador-criatura", tan característica de la fe católica y que es propia de la influencia franciscana en la santa limeña, que propicia esa apertura al amor de Dios y a la naturaleza, en sí del amor espiritual y de amor cortesano. Así, la relación entre la naturaleza y Rosa de Lima es plasmada en el arte, en el que siempre se aprecia un elemento de la creación. Ejemplo nuevamente de ello lo encontramos en la pintura cusqueña, tal como podemos apreciar en la figura $\mathrm{N}^{\circ} 3$, referida a un anónimo cusqueño del siglo XVIIII. 


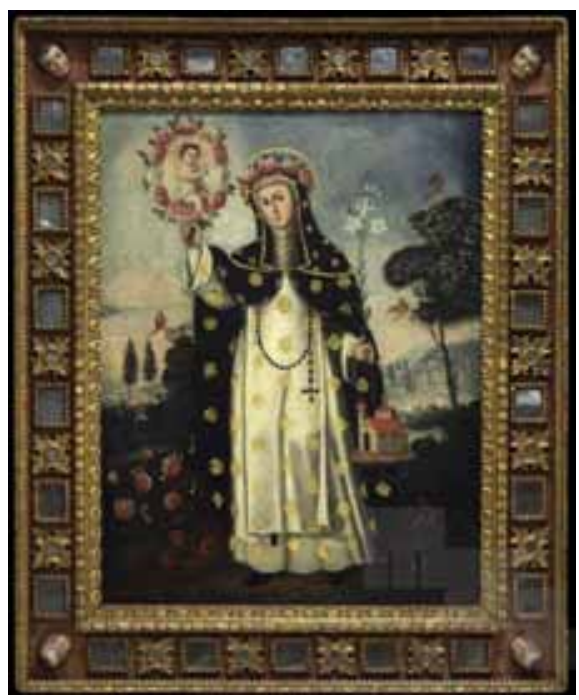

Figura $N^{\circ} 3$. Santa Rosa de Lima (ca. 1740-1770), anónimo cuzqueño. Fuente: Museo de Arte de Lima. Donación Pedro de Osma.

También en sus coplas se encuentra la invocación a su ángel de la guarda, a quién le dedicó esta devoción que refleja que, a pesar de sus aflicciones corporales, levantaba su espíritu y consuelo hacia Dios:

Ángel de mi Guarda

Vuela y di a mi Dios

Que por qué se tarda,

(Carrasco Ligarda, 2016: 164).

Esta copla, a decir de Carrasco Ligarda (2016: 191), "presenta una invocación apelativa en el modo de transmisión del mensaje al mensajero y al destinatario, pero queda en la indeterminación la respuesta que el yo desea. Este acto alocutivo es el nexo entre la realidad empírica y la espiritual del ángel y Dios, nexo que se establece directamente". Rosa de Lima busca la conexión, anhela una respuesta espiritual de su creador y "utiliza" la figura del ángel para el logro de su objetivo, una suerte de complicidad que conlleva al ruego y al mandato.

Del Busto (2006: 283) nos dice que Rosa de Lima estaba ocupada continuamente "en cantarcillos de alabanzas a Dios, y en regalos y requiebros al Niño Jesús, de quien fue muy devota”. También, conforme a los testimonios, en su proceso de canonización se señala: “Deus in ad- 
jutorium deum intende; Domine, ad adjuvanum me festina". Del Busto, respecto de este hecho, nos informa: "Intrigado, su hermano Hernando le tornó a preguntar otra vez qué quería decir con ello. Rosa lo satisfizo diciéndole "que su madre Santa Catalina de Siena lo repetía muy a menudo; y pues es mi madre, la quiero imitar".

Sus coplas, que son diversas, nos llevan a entender el anhelo de Santa Rosa de Lima, que era amar a Dios con aspiración sublime e impotente. Sin embargo, no se quiere encajar a la santa limeña como una poeta $o$ escritora acérrima, sino mostrar que su alma era sincera y que encerraba una armonía clara y acorde también a la época y a la vida de otras santas.

\section{Mercedes y Escala Mística}

El tema de la mujer, inmersa en el mundo literario durante el virreinato, ha sido abordado por los historiadores. Vinatea Recoba (2008: 147-148) señala que es importante considerar el estudio de estas mujeres de la época virreinal, y que esto se justifica en el hecho de que se piensa comúnmente que la mujer no tuvo participación en la historia o que su papel se reduce a ser anónima y sufriente; sin embargo, en donde debemos buscar no es en los espacios públicos - tal es el caso de los hombres-, sino en los espacios privados: la casa y el convento, principalmente. Así, para la historiadora, las investigaciones que reconstruyan los espacios femeninos y su quehacer cotidiano nos llevarán a su literatura, la que nos permitirá acercarnos con mayor justicia a su historia.

Centrándonos en Rosa de Lima, nos inclinamos a presumir que debió de oír la lectura de biografías u obras piadosas en su tiempo, y la lectura de la vida de santa Catalina de Siena; posteriormente, leerla escrita por el beato Raimundo de Capua o, también, darse a la lectura de autores místicos de la altura de Fray Luis de Granada. Fueron quizás diversos libros los que consultó la santa, y esto se evidencia en las declaraciones conforme al proceso de canonización. Sin embargo, creemos que está muy lejos de ser reconocida doctora de la Iglesia. A pesar de ello, tenemos aportes culturales muy loables de su vida, como lo son sus Mercedes y Escala Mística.

Para esto, antes de iniciar un breve recorrido por estas obras, debemos determinar si la santa limeña puede ser denominada como una escritora de la época virreinal. A nuestro entender, es aventurado calificarla como tal, debido a su menuda contribución en este género. Una 
de las posturas interesantes acerca de su calidad de escritora es la propuesta por Vinatea Recoba, quién considera a Rosa de Lima como una escritora de beatario; en vista de que las "beatas e iluminadas escribían voluminosos diarios que daban cuenta de sus 'coloquios con el cielo"' (Vinatea Recoba, 2008: 156). Sin embargo, considera la historiadora que este tema debe ser estudiado con mayor profundidad.

Ahora, si ahondamos en la producción intelectual de Rosa de Lima encontramos, además de sus coplas, sus Mercedes, las cuales aceptó humildemente escribir por inducción de sus confesores. Rosa solicita a su confesor que, al revisarlas, "enmendase lo que en dicha obra faltare por mi ignorancia", y que de ser necesario las quemase: "Muchos yerros y faltas se ayara por ser explicada de mi mano, y si se ayare que es bueno será solo por haber sido las mercedes de Dios" (Graziano, 2002: 18).

Las Mercedes de Rosa de Lima consisten en dos pliegos con dibujos, de puño y letra de la santa, que manifiestan su espiritualidad. Descubiertos en 1923 por el historiador dominico fray Luis Alonso Getino, quien visitó el monasterio de Santa Rosa, encontrando en su habitación las Mercedes, a las cuales no se les había dado importancia hasta ese momento. También en ese descubrimiento se halla la Escala Místi$c a$, que tiene como contenido un conjunto de dibujos que nos llevan a un conjunto de escalones o grados de amor perfecto a Dios.

Al final, constituyen dos medios pliegos que "representan en forma significante las experiencias místicas de Rosa de Santa María. La expresión brota de la vivencia subjetiva que le da sentido (...). Estos textos posiblemente estén entre los pocos que acuden a la ilustración gráfica para expresar el encuentro humano con la divinidad" (Carrasco Ligarda, 2016: 31). Así, en las Mercedes, la santa nos dice que son "hechas todas a un enamorado corazón. Tiernamente enamorada de Dios - a una sierva de Christo indigna de ser contada entre los hijos de Dios, estampadas aquí (con particular luz del cielo la corrección pido del Verbo)" (Carrasco Ligarda, 2016: 44).

Así, la forma de expresarse de la santa se invade de recursos de carácter expresivo, como dibujos, combinando con palabras, colores y recortes de papel (figura $\mathrm{N}^{\circ} 4$ ) que, de acuerdo con Carrasco Ligarda (2016: 32), "forma iconos en una composición donde el espacio se re- 
semantiza y se convierte en parte del mensaje. Se trata de una síntesis expresiva compleja que se puede denominar iconotexto". Apunta también Del Busto a que tanto las Mercedes como la Escala Mística fueron realizadas de repente, el mismo día, dirigidas a un padre espiritual al que Rosa trata de "vuestra paternidad", por ser sacerdote, el cual podría ser el dominico fray Juan de Lorenzana o el jesuita Diego de Martínez.

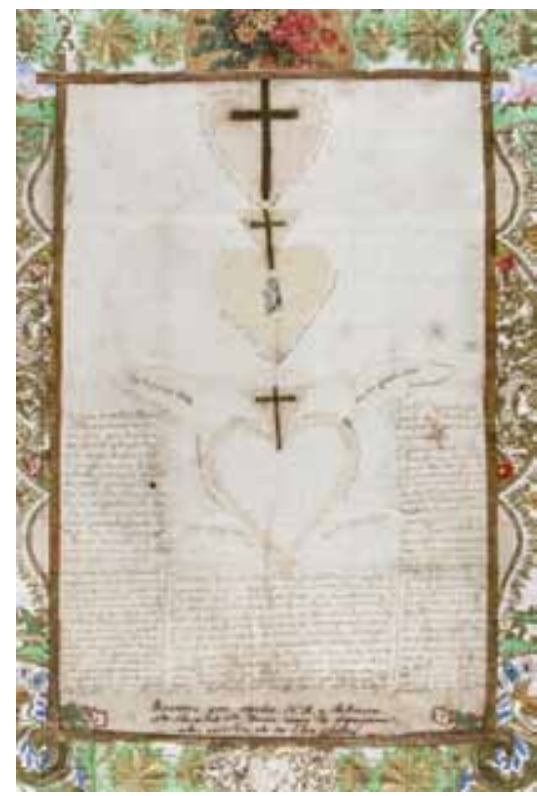

Figura $N^{\circ} 4$. Las tres Mercedes concedidas a Santa Rosa entre 1611 y 1616.

Fuente: Monasterio de Santa Rosa de Lima, Cercado - Creaciones de Santa Rosa de Lima: Repositorio Institucional de la Pontificia Universidad Católica del Perú.

Estas Mercedes, elaboradas por Rosa de Lima, nos llevan a su enamorado corazón que se dirige de manera tierna a Dios, lo que implica un acto humilde y de ofrecimiento al Señor; sin embargo, ella reitera su autoría, sosteniendo que lo hecho es por inspiración divina y que lo aprendido es fruto del trato intimo con Dios: "Confieso con toda verdad en presencia de Dios que todas las mersedes que [he] escrito así en los quadernos como esculpidas y retratadas en estos dos papeles, ni las he visto ni leído en libro alguno. Solo si obradas en esta pecadora, de la poderosa mano del Señor, en cuyo libro leo, que es sabiduría eterna, quien confunde a los soberbios y ensalza a los humildes" (Mujica Pinilla, 2020: 18). 
A su vez, estas Mercedes están acompañadas de unos dibujos como corazones y cruces, que se aprecian también en su Escala Mística. Estos dibujos son de color rojo tenue, casi naranja, siendo tres ubicados verticalmente cada uno con una cruz latina que representa el calvario y la pasión de Cristo. Rosa, muy hábil con la aguja e hilo, los ha recortado y pegado uno debajo del otro, para ilustrar gráficamente el inicio de la secuencia de comunicaciones o gracias místicas en su camino de unión con Dios. También, estos vienen acompañados como experiencia mística por la palabra o lemas explicativos que nos permiten entender el camino hacia Dios.

El primer corazón de las Mercedes tiene la siguiente frase: "Primera merced de eridas que recevi de Dios con lansa de asero me irió y se escondió". El segundo corazón es a mí entender el que demuestra la ternura de la santa, un corazón con una cruz en su parte superior y el Niño adentro: “Aquí descansó Jesús abrasándome el corazón”. Al último y tercer corazón, que sigue llevando la cruz en lo alto, le han nacido cuatro alas en las que se lee: “Buela para Dios", en cuyo límite se encuentra la frase: "El campo del corazón lo llenó Dios de suave amor asiendo morada en él".

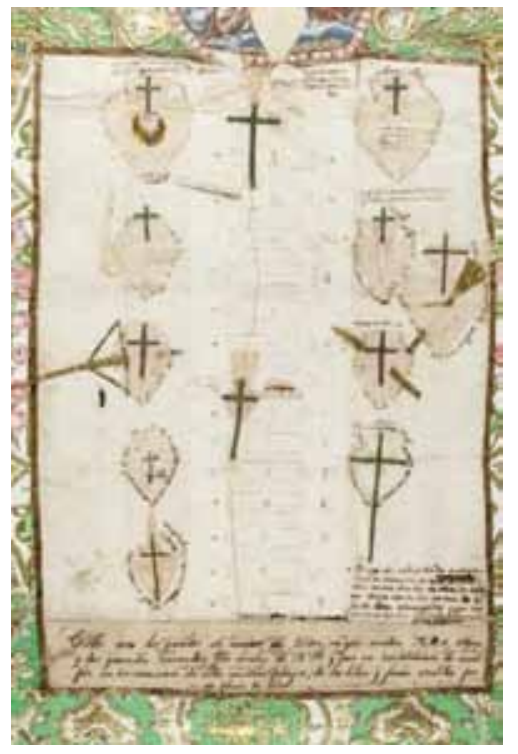

Figura $N^{\circ}$. Las Mercedes en la escala mística del amor de Dios.

Fuente: Monasterio de Santa Rosa de Lima, Cercado - Creaciones de Santa Rosa de Lima: Repositorio Institucional de la Pontificia Universidad Católica del Perú. 
Por su parte, la Escala Mística (figura $\mathrm{N}^{\circ} 5$ ) repite la secuencia de los corazones, dibujos y lema de sus Mercedes. Carrasco Ligarda (2016: 21) dice que este pliego es "una composición que se distribuye en tres espacios diferentes, con dos columnas de corazones y al centro una escala". Podemos rescatar de esta Escala Mística que el símbolo se convierte en el "medio más apropiado para expresar lo religioso" y llevarnos quizás a las experiencias místicas de la santa limeña; nos ayuda a adentrarnos a la vida íntima de la santa a partir de una creación propia y novedosa.

De lo visto, lo cual implica un pequeño recorrido sobre la labor intelectual de la santa limeña, podemos decir que sus frases tienen sentido y contenido más místico que teológico. A su vez, sus dibujos son floridos, no gozan de mucho arte, pero tienden a ser entendibles y no complicados que nos llevan exactamente a lo que la santa quiere mostrar: su cercanía con el Creador. Lo visto, a su vez, nos inclina a afirmar que aún existe material documental digno de ser investigado y analizado.

Asimismo, queremos recalcar que no se pretende otorgar a Rosa la calidad de gran escritora mística o doctora de la Iglesia, así como la de catalogarla como una eximia dibujante y gran compositora de coplas y cánticos. La santa limeña no pretendió ser artista, sus dibujos son pobres artísticamente, pero llenos de gloria desde un punto de vista místico; sus cánticos, verdaderas alabanzas puras y llenas de amor a su creador.

\section{Referencias bibliográficas}

a) Artículos y capítulos de libros

Graziano, F. (2002). "Santa Rosa de Lima y la política de canonización", en Revista Andina, $\mathrm{N}^{\circ} 34$, pp. 9-39.

Vinatea Recoba, M. (2008). "Mujeres escritoras en el virreinato peruano durante los siglos XVI y XVII", en Histórica, vol. 32, $\mathrm{N}^{\circ} 1$, pp. 147-160.

b) Libros

Carrasco Ligarda , R. (2016). Santa Rosa de Lima: Escritos de la Santa Limeña. Lima: Facultad de Teología Pontificia y Civil de Lima. 
Del Busto, J. (2006). Santa Rosa de Lima: Isabel Flores de Oliva. Lima: PUCP.

Hansen, L. (1895). Vida admirable de Santa Rosa de Lima, patrona del Nuevo Mundo.

Martín, L. (2000). Las hijas de los conquistadores. Mujeres del virreinato del Perú. Barcelona: Casiopea.

Mujica Pinilla, R. (2004). Rosa Limensis: Mística, política e iconografía en torno a la patrona de América. Lima: Fondo de Cultura Económica, Banco Central de Reserva, Instituto Francés de Estudios Andinos.

Muriel, J. (1992). Las mujeres de hispanoamérica - Época Colonial. Madrid: Mapfre. 